\title{
The effects of sensory distractions on short-term recall of children with attention deficit-hyperactivity disorder versus normally achieving children
}

\author{
PAULA HIGGINBOTHAM and CARL BARTLING \\ McNeese State University, Lake Charles, Louisiana
}

\begin{abstract}
Children diagnosed with attention deficit-hyperactivity disorder (ADHD) often have difficulties in learning, attributable, in part, to varying attention. Learning requires the use of memory. However, children may often miss a word or phrase that is essential to the processing of information, memory, and learning. This study addressed short-term recall in 11 children with ADHD and 8 normally achieving children (matched for age and grade) on repetitive tasks involving auditory, visual, and combined distractions. The children with ADHD performed more poorly in the middle and end (but not at the beginning) of a short-term recall task than did the normally achieving children matched for age and grade. Both groups of children showed a decrement in performance on the short-term recall task from the beginning to the middle to the end of the task. However, the decrement in performance directly attributable to specific sensory distractions was relatively small (about $2 \%-14 \%$ ) and statistically nonsignficant in comparison with decreases in performance attributable to increasing proactive interference, increasing difficulty of the statements from begining to end of a 30 -statement set, and other factors.
\end{abstract}

Children diagnosed with attention deficit-hyperactivity disorder (ADHD) often have difficulties in learning, in comparison with children of equivalent intelligence who do not have an attention deficit disorder or learning disability (Hunsucker, 1988; Knights \& Bakker, 1980; Silver, 1990, 1992). To learn, children must first adequately attend to and process information that is to be retained. Some children (particularly children with ADHD) are more easily distracted by extraneous stimuli that are irrelevant to the information to be retained in school or in other settings. Distractibility is one of the central characteristics that is used in the diagnosis of ADHD. Thus, it seemed reasonable to the present authors that there should be an extensive body of research about contextual and sensory features of competing information that might influence the distractibility of children with ADHD. We found, however, that few articles directly addressed these issues. Nevertheless, the following summary provides information that is at least tangential to them.

Knights and Bakker (1980) state that "children have difficulty connecting on relevant input because of the degree of vulnerability to (or an inability to screen out) irrelevant stimulation. As a result, task performance is easily disturbed whenever task-irrelevant stimuli are present"' (p. 66).

Borcherding et al. (1988) tested children with ADHD and controls "on verbal memory tasks differentiating au-

Requests for reprints should be sent to C. Bartling, Department of Psychology, McNeese State University, Lake Charles, LA 70609. tomatic versus effortful information processing"' (p.333). Their results showed that "effortful cognition ... is more dependent on related psychological processes such as affect, motivation and arousal" (p. 342).

Silver (1992) explains that

Some children who are distractible appear to be able to attend to certain tasks for long periods of time. Parents may question if their child is distractible if he or she can spend hours watching television or playing a video game. These tasks are usually ones that are enjoyable and where the motivation is high. It appears that to be able to focus like this, these individuals have to apply extra "filters" to block out superfluous stimuli. They appear to be in a trance. Parents report they can talk to these children, but they do not respond. To get their attention, the parents must shake them or stand between them and the activity. Then they may say, "huh?'" and respond. (p. 12)

According to the Diagnostic and Statistical Manual of Mental Disorders (DSM III-R; American Psychiatric Association, 1987), ADHD is diagnosed according to certain core conditions, with the emphasis on degree. "Symptoms typically worsen in situations requiring sustained attention, such as listening to a teacher in a classroom" (p. 50).

However, "because the symptoms differ from child to child," states Hunsucker (1988), "diagnosing attention deficit disorder is sometimes difficult" (p. 10). The DSM $I I I-R$ states that in the many settings in which the disorder manifests itself, degree is of importance. According to the DSM III-R, "some show signs of the disorder in only one setting, such as at home or at school" (p. 50). 
Sondra S. Myers (personal communication, October 18, 1992), an experienced elementary school principal, has emphasized that students in Grades 3 and 4 have a greater demand for sustained listening than do those in previous grades. These students therefore need to filter distractions to a greater degree for task completion.

Children with ADHD fail to receive entire messages, which may seriously hinder academic performance or performance on other related tasks (Knights \& Bakker, 1980). Knights and Bakker refer to a paper by Douglas and Peters (cited in Knights \& Bakker, 1980), who hypothesize that "most of the behavior and cognitive abnormalities of hyper children can be attributed to defective functioning in three closely related mechanisms ... (1) sustained attention and effort, (2) inhibitory control, and (3) the modulation of arousal levels to meet task or situational demands" (p. 67). Zentall and Meyer (1987) explain that "children with a high need for stimulation (hyperactive children or attention-disordered children with hyperactivity) demonstrate a higher rate of sensation-seeking activity and attraction to novel stimulation"' (p. 520).

Research thus far has indicated a strong correlation between attention and hyperactivity, which suggests a problem in the brain. Memory recall is thought to involve various parts of the brain, with specialized areas working together to combine events. Bootzin, Bower, Crocker, and Hall (1991) describe the reticular activating system as the part of the brain that "helps focus our attention, perhaps by selectively blocking incoming sensory stimuli"' (p. 59).

Silver (1990) postulates that ADHD is a "presumed neurological disorder that impacts on the ability to control motor activity level (hyperactivity), to determine which external stimuli are relevant (distractibility), and to reflect before acting (impulsivity)" (p. 395). Silver (1992) reports that "visually distracted children may be distracted by the design on a rug or a picture or other objects in the room. If outside, they will notice birds flying, clouds going by, or the trees and not stay focused on the appropriate activity ... and the original task is never completed" (p. 12). It was concluded in this study that a deficit in sustained attention referenced with visual distractors best describes the difference between children with ADHD and normally achieving comparison children. This seems significant in relation to another topic for future research: Many children with ADHD comment that they can concentrate better with music being played.

The purpose of the present study was to test the shortterm recall of children diagnosed with ADHD and of comparison children, in repetitive tasks with auditory, visual, and combined distractions. We expected the distractions to disrupt short-term recall for both groups of children in our study. However, we assumed that children with ADHD would be more vulnerable to distractions than would normally achieving children without attention deficit disorders. Thus, we expected to find different patterns of disruptions of short-term recall across the two groups of children in our study. Our predictions were based on our general knowledge of information process- ing theory and on more specific studies of children with ADHD.

\section{METHOD}

\section{Subjects}

Subjects volunteered from two public schools; they were 19 third and fourth graders matched for age/grade level across two groups. Eleven children were diagnosed professionally and/or were on medication for ADHD. Eight normally achieving children matched for age and grade served as a control group. The school principals and guidance counselors coordinated subject selection for reasons of confidentiality. At the time of experimentation, the children with ADHD who were on medication had taken it within $2 \mathrm{~h}$ of testing.

The subjects had a mean age of 8.74 years and ranged from 8 to 10 years. Fifteen of them were boys, and 4 , girls; 14 were white, and 5 , black; 14 were in the third grade, and 5 , in the fourth grade. All came from a small southern town with a population of approximately 7,000 people.

\section{Design and Procedure}

Type of distraction (auditory, visual, combined, or no distraction) was a within-subjects variable. The number of each type of distraction per student varied slightly, because the researchers tested the children in their school environment (an empty classroom) to enhance the ecological validity of the study. Therefore, we used proportion scores instead of number of correct responses in our data analyses to adjust for these small differences in number of distractions presented to each student (see the Results section). An examiner (the senior author of this study) and assistant used standardized instructions and procedures.

The researchers tested the children on recall tasks (The Test of Language Development-2) designed by Newcomer and Hammill (1988), with interval distractions of visual, auditory within earshot, and visual and auditory combined, as well as with no distractions. Each child was tested individually on short-term recall of 30 statements ranging in difficulty from a sentence such as, "Her friends walked to school," to a sentence such as, "They gave the lion who had become very dangerous to the zoo"' (pp. 19-20).

The following are examples of distractions used: auditory-the assistant dropping a book outside of the testing room; visual-the assistant quietly walking across the testing room and exiting from the room; and combined auditory and visual-the assitant entering the room, walking past the child, sorting through papers within view and earshot of the child, and then exiting from the testing room. The researchers selected these specific types of distractions to meet two criteria; they had to be (1) events that teachers report as commonly occurring in classroom settings, and (2) events that we could reliably reproduce. Type of distraction was quasirandomly distributed across blocks of 10 statements. The researchers also presented some of the statements within each block of 10 without any specific distraction present.

The basis of this mixed factorial design was to measure distractibility as well as sustained attention. The children were required to try to repeat each of the 30 statements exactly as it was said to them. The researchers rated the children's responses as either correct or incorrect.

\section{RESULTS}

The unit of comparison for the short-term recall scores was the proportion correct per block of 10 statements for the group with ADHD and the control group, with and without distractions. Blocks of 10 statements were used because of a clear pattern of decrease in performance for both groups as a function of serial position (1-30) of the statements read to them. The three types of distractions were collapsed into a single category, since there were no significant differences in performance across the three types of distractions. In Table 1, short-term recall per- 
Table 1

Short-Term Recall Performance of Attention Deficient-Hyperactivity Disorder (ADHD) Group and Control Group, With and Without Distractions, Across Blocks of 10 Statements

\begin{tabular}{|c|c|c|c|c|c|c|}
\hline \multirow[b]{3}{*}{ Group } & \multicolumn{6}{|c|}{ Statements } \\
\hline & \multicolumn{2}{|c|}{$1-10$} & \multicolumn{2}{|c|}{$11-20$} & \multicolumn{2}{|c|}{$21-30$} \\
\hline & Dis & No Dis & Dis & No Dis & Dis & No $\mathrm{Di}$ \\
\hline ID $1 n-1$ & 0.94 & 0.91 & 0.62 & 0.76 & 0.29 & 0.41 \\
\hline Controls $(n=8)$ & 0.94 & 0.90 & 0.80 & 0.91 & 0.53 & 0.55 \\
\hline
\end{tabular}

Note-Dis, distractions; No Dis, no distractions. The recall tasks were designed by Newcomer and Hammill (1988).

formance is shown as a function of group (ADHD vs. control group), distraction condition (with vs. without distractions), and block of 10 statements (first $10 \mathrm{vs.} \mathrm{second}$ 10 vs. third 10 statements). Distraction condition and block of 10 statements were both within-subjects variables for the resulting 2 (between) $\times 2$ (within) $\times 3$ (within) mixed factorial design.

The data in Table 1 show (1) a decrement in performance across the three blocks of 10 statements for both groups of children $\left[F(2,28)=68.51, M S_{\mathrm{e}}=.027, p<\right.$ $.0001]$; (2) no difference across the two groups or across the distraction condition, within the first block of 10 statements (performance range, $90 \%-94 \%, F \mathrm{~s}<1$ ); (3) a greater decrement in performance during the second and third blocks of 10 statements for the group with ADHD in comparison with the control group [e.g., 30\%-36\% for the group with ADHD for the last 10 statements vs. $51 \%-56 \%$ for the control group; $F(2,28)=3.64, M S_{\mathrm{e}}=$ $.027, p<.05$, for the block $\times$ group interaction]; (4) only a small, nonsignificant decrement in performance (range, $2 \%-14 \%$ ) for the distraction condition in comparison with the no-distraction condition for both groups of children $[F(1,14)<1]$; and $(5)$ a marginally significant difference in short-term recall performance between the group with ADHD and the control group $\left[F(1,14)=3.11, M S_{\mathrm{e}}=\right.$ $.106, p<.10]$.

The preceding data analyses were conducted on the scores from 9 of the 11 children with ADHD and 7 of the 8 children from the control group. Two of the children with ADHD and one of the children from the control group had one or more undefined scores (i.e., no statement of a given type-with or without distractionspresent within a block of 10 statements). The pattern of the data and the conclusions drawn from the data analyses are not changed if the partial data from these 3 children are included in the data analyses. Also, when the data are collapsed across subjects before calculating proportion scores for the short-term recall measure, the pattern of data and conclusions drawn are unchanged.

\section{DISCUSSION}

The children with ADHD recalled fewer statements correctly than did the children in the normally achieving group for the second and third blocks of 10 statements. Surprisingly, both groups of subjects performed only slightly more poorly $(2 \%-14 \%$ decrement) because of the specific distractions presented with some of the statements as opposed to others. Other explanations are necessary if one is to understand why the children with ADHD performed more poorly on the latter two thirds of the statements than did the children in the control group.

Knights and Bakker (1980) found that children who display symptoms of hyperactivty have "difficulty connecting on relevant input because of a high degree of vulnerability to (or an inability to screen out) irrelevant stimulation"' (p. 66). Since a within-subjects design with respect to the sensory-distraction/no-distraction variable was used in the present study, it is possible that instead of a specific distraction effect, a general distraction effect occurred that influenced the children with ADHD more than the children in the control group. This hypothesis could be tested experimentally by comparing groups of subjects' short-term recall performance in a within-subjects condition for the distraction variable for one group and between-subjects conditions for the distraction variable for the other groups.

Other factors probably should be considered as well. It is very likely that two important factors influenced poorer performance for both groups of children in the present study as the $\mathbf{3 0}$ statements progressed in sequence: (1) increasing proactive interference on short-term recall, and (2) the increasing length and/or difficulty of the statements from Statement 1 to Statement 30.

Proactive interference (or proactive inhibition) affects performance in short-term recall tasks by making it more difficult for subjects to distinguish or recall new material over a lengthy series of trials. Performance is usually good on the first few trials in a short-term recall task, but decreases with successive items to be remembered, particularly when the to-be-remembered items are somewhat alike (Brown, 1958; Peterson \& Peterson, 1959). With the task in the present study, both the number of items tested (30) and the increasing length and difficulty of the statements from the beginning to the end of the set would increase the importance of secondary or long-term memory processes relative to shortterm memory processes. (Crowder's, 1976, textbook chapter on forgetting in short-term recall [pp. 176-216] is one of the better summaries of this topic.)

Borcherding et al. (1988) postulated that the "automatic and effortful processing distinction may be useful in the search for primary deficits in attention deficit/hyperactivity disorder by focusing research on effortrelated variables such as affect, arousal, self-regulation, and motivation" (p. 343). Additional research will be necessary if we are to pinpoint more specifically the factor or factors that caused the poorer shortterm recall performance for the children with ADHD in comparison with the children in the control group in the present study. The outcome of such research may have both theoretical and applied implications. For example, if children with ADHD are more susceptible to proactive interference than normally achieving children without ADHD, it may be necessary for teachers to adopt teaching strategies to reduce proactive interference for children with ADHD. This would include changing types of learning tasks more frequently for children with ADHD than for other children. Other possible research outcomes may suggest a need to teach learning strategies to children with ADHD to enhance their long-term memory encoding capabilities.

\section{REFERENCES}

American Psychiatric Association (1987). Diagnostic and statistical manual of mental disorders (3rd ed. rev.). Washington, DC: Author.

Bootzin, R. R., Bower, G. H., Crocker, J., \& Hall, E. (1991). Psychology today: An introduction (7th ed.). New York: McGraw-Hill. Borcherding, B., Thompson, K., Kruesi, M., BArtKo, J. J., RAPOPORT, J. L., \& WeINGARTEN, H. (1988). Automatic and effortful processing in attention deficit/hyperactivity disorder. Journal of Abnormal Psychology, 16, 333-345.

Brown, J. (1958). Some tests of the decay theory of immediate memory. Quarterly Journal of Experimental Psychology, 10, 12-21.

Crowder, R. G. (1976). Principles of learning and memory. Hillsdale, NJ: Erlbaum. 
HunSUCKer, G. (1988). Attention deficit disorder: A common but often overlooked disorder of children. Fort Worth, TX: Forresst.

KNIGHTS, R. M., \& BAKKER, D. J. (Eds.) (1980). Treatment of hyperactive and learning disordered children. Baltimore: University Park Press.

Newcomer, P. L., \& Hammill, D. D. (1988). Test of language development-2. Austin, TX: Pro-Ed.

Peterson, L. R., \& Peterson, M. J. (1959). Short-term retention of individual verbal items. Journal of Experimental Psychology, 58, 193-198.
Silver, L. B. (1990). Attention deficit-hyperactivity disorder. Journal of Learning Disabilities, 23, 394-397.

SILVER, L. B. (1992). Attention-deficit hyperactivity disorder: A clinical guide to diagnosis and treatment. Washington, DC: American Psychiatric Press.

Zentall, S. S., \& MeYer, M. J. (1987). Self-regulation of stimulation for ADD-H children during reading and vigilance task performance. Journal of Abnormal Child Psychology, 15, 519-536.

(Manuscript received May 17, 1993.) 